\title{
AWM at 50 and Beyond
}

\section{Georgia Benkart, Kristin Lauter, and Sylvia Wiegand}

All three authors have been presidents of the AWM: Sylvia Wiegand from 1997 to 1999, Georgia Benkart from 2009

to 2011, and Kristin Lauter from 2015 to 2017.

This year-2021 - the Association for Women in Mathematics (AWM) turns 50, March is Women's History month, and last August we celebrated the hundredth anniversary of women winning the right to vote in the United States (August 18, 1920). Thus it is a good time to take stock of the state of affairs for women in mathematics, and to give an update on the many programs and initiatives launched and run by the AWM on behalf of women and girls in mathematics.

The AWM's mission is "to encourage women and girls to study and to have active careers in the mathematical sciences, and to promote equal opportunity and the equal treatment of women and girls in the mathematical sciences." To achieve this mission, the AWM offers programs and activities that support and encourage women in the mathematical sciences at all levels. The AWM is an organization almost entirely powered by volunteers, more than 200 of whom serve on the many committees that run all the AWM programs. As noted in "AWM in the 1990s" [TaylorWiegand], which appeared in the Notices close to the AWM's thirtieth birthday, the AWM's members and volunteers are passionate about the goals of the AWM. In this article, we focus on the association's activities and achievements since then, particularly those that the authors are most familiar with. We also provide some observations on how the status of women has changed in the interim.

Georgia Benkart is a professor emerita of mathematics at the University of Wisconsin-Madison and an associate secretary of the AMS. Her email address is benkart@math.wisc.edu.

Kristin Lauter is a principal researcher and partner research manager at Microsoft Research and affiliate professor at the University of Washington. Her email address is k1auter@microsoft.com.

Sylvia Wiegand is a professor emerita of mathematics at the University of Nebraska Lincoln. Her email address is swi egand1@un1. edu.

For permission to reprint this article, please contact: reprint-permission aams.org.

DOI: https://dx.doi.org/10.1090/noti2239
According to the 2016-2017 report on new doctorate recipients [Golbeck-Barr-Rose], women received 29\% of the PhDs awarded in mathematics from 1991-2015, but still comprised only $17 \%$ of the tenured/tenure-eligible faculty at PhD-granting institutions. The situation is even worse at elite institutions, which typically provide better access to resources to support research activities. It has improved slightly this year, however, as Harvard has just hired two new female full professors for AY 2020/21, bringing its total to three. A study of 435 mathematics research journals found that only $8.9 \%$ of editors were women [Topaz-Sen]. Many mathematicians were encouraged by the progress at the International Congress of Mathematicians (ICM) 2014 in Seoul, which highlighted three women-Maryam Mirzakhani, the first woman Fields Medalist, Ingrid Daubechies, the first woman president of the International Mathematical Union, and, Park Geun-hye, the first woman president of South Korea-but the most recent ICM in Brazil in 2018 again saw none of the major research prizes awarded to women. Tables 1-3 show women faculty at elite institutions in 2019-2020, 1991-1992, and 1998-1999.

For many years, leaders of the AWM have tried various approaches to address three major problems confronting women mathematicians: the underrepresentation of women and minorities in research mathematics; the lack of equity in resources, awards, and access; and the barriers to career advancement for women and underrepresented minorities in the mathematical profession. For instance, it is AWM policy that the AWM President write letters to conference organizers who have no women speakers at their conferences and to chief editors of key research journals with no women on their editorial boards. Similarly, AWM Presidents have advocated to the AMS Council for more diversity on the editorial boards of AMS journals and have written to presidents of major institutions to urge them to hire more women into their mathematics faculties. 
HISTORY

Department

Tenured

Assistant Professors

\begin{tabular}{ccccc}
\hline & Total & Female & Total & Female \\
\hline UC Berkeley & 56 & $9.5^{*}$ & 4 & 0 \\
Caltech & 22 & 3 & 0 & 0 \\
Chicago & 36 & 3 & 4 & 1 \\
Columbia & 28 & 4 & 4 & - \\
Harvard & 17 & 1 & - & 1 \\
MIT & 45 & 5 & 4 & 1 \\
Michigan & 59 & 12 & 1 & 3 \\
Princeton & 32 & 3 & 1 & 0 \\
Stanford & 24 & 2 & 1 & 0 \\
Yale & 14 & 1 & 36 & 7 \\
Total & 333 & 42 & & \\
\hline
\end{tabular}

* One appointment is half time in physics.

Table 1. Women in mathematics, 2019-2020 [from Cathy Kessel]

For comparison, below are the figures from [Taylor-Wiegand]:

\begin{tabular}{|c|c|c|c|c|c|c|}
\hline \multirow[t]{2}{*}{ Department } & \multicolumn{2}{|c|}{ Tenured } & \multicolumn{2}{|c|}{ Untenured } & \multicolumn{2}{|c|}{ Tenure-Track } \\
\hline & Total & Female & Total & Female & Total & Female \\
\hline UC Berkeley & 60 & 2 & 12 & 3 & 2 & 0 \\
\hline Caltech & 13 & 0 & 6 & 0 & 1 & 0 \\
\hline Chicago & 25 & 0 & 24 & 2 & 6 & 0 \\
\hline Columbia & 14 & 1 & 12 & 0 & 0 & 0 \\
\hline Harvard & 17 & 1 & 14 & 3 & 1 & 0 \\
\hline MIT & 40 & 0 & 38 & 4 & 12 & 1 \\
\hline Michigan & 49 & 1 & 38 & 6 & 3 & 1 \\
\hline Princeton & 31 & 0 & 28 & 7 & 22 & 5 \\
\hline Stanford & 23 & 0 & 9 & 1 & 2 & 0 \\
\hline Yale & 16 & 0 & 11 & 1 & 3 & 0 \\
\hline Total & 288 & 5 & 192 & 27 & 52 & 7 \\
\hline
\end{tabular}

Table 2. Women in mathematics, 1991-1992.

\section{AWM Advances!}

The continuing paucity of women faculty at research departments challenges the profession to look for new solutions. Although documenting and calling attention to inequity remain necessary, the AWM must expand its five-decade effort to build community in order to directly support women in mathematics and to proactively increase the opportunities, success, and visibility of women in mathematics. As a significant step in this direction, in 2015 the AWM received a five-year, $\$ 750,000$ ADVANCE grant to build and sustain research networks for women in all areas of mathematics.

The AWM ADVANCE Grant: Career Advancement for Women through Research-Focused Networks

The goal of the AWM ADVANCE grant is to create long-term change through communities of women supporting each other in research. Its specific model is to launch Research Networks for Women that can help advance their careers in 


\begin{tabular}{|c|c|c|c|c|c|c|}
\hline \multirow[t]{2}{*}{ Department } & \multicolumn{2}{|c|}{ Tenured } & \multicolumn{2}{|c|}{ Untenured } & \multicolumn{2}{|c|}{ Tenure-Track } \\
\hline & Total & Female & Total & Female & Total & Female \\
\hline UC Berkeley & 60 & 2 & 12 & 3 & 2 & 0 \\
\hline Caltech & 12 & 0 & 3 & 0 & 3 & 0 \\
\hline Chicago & 31 & 0 & 24 & 3 & 8 & 0 \\
\hline Columbia & 17 & 1 & 13 & 2 & 0 & 0 \\
\hline Harvard & 16 & 0 & 14 & 2 & 0 & 0 \\
\hline MIT & 36 & 0 & 40 & 10 & 12 & 4 \\
\hline Michigan & 58 & 4 & 44 & 9 & 1 & 0 \\
\hline Princeton & 23 & 2 & 20 & 3 & 14 & 1 \\
\hline Stanford & 22 & 0 & 9 & 1 & 2 & 1 \\
\hline Yale & 15 & 0 & 8 & 0 & 1 & 0 \\
\hline Total & 288 & 9 & 183 & 31 & 42 & 6 \\
\hline
\end{tabular}

Table 3. Women in mathematics, 1998-1999.

a scalable way, and then connect them back to the broader mathematical research community where women are underrepresented.

After five years, the AWM ADVANCE grant has already achieved extraordinary success (see https:// awmadvance. org/ for more information):

- launching and supporting 23 Research Networks for Women in all areas of mathematics,

- supporting five to ten Research Collaboration Conferences per year for women in these networks,

- publishing 22 volumes of research articles in the AWM Springer Series,

- supporting AWM workshops at the Joint Mathematics Meetings (JMM) and the SIAM annual meetings to highlight the research from these networks,

- supporting the biennial AWM Research Symposium featuring the work of roughly 350 women researchers in more than 20 special sessions,

- involving more than 2,000 women researchers in mathematics worldwide, and

- creating email and mentoring networks tied to research fields which help to strengthen the pipeline for women in mathematics.

The great success of the WIN (Women in Numbers) Number Theory Network, founded in 2006 by Kristin Lauter, Rachel Pries, and Renate Scheidler, inspired the AWM to initiate Research Networks for Women in other areas of mathematics. Research Networks for Women are formed as a result of Research Collaboration Conferences for Women (RCCWs). The RCCWs are week-long conferences, held at mathematics institutes or universities, where junior and senior women come together to work on predefined projects. For example, at the first WIN conference in 2008 at the Banff International Research Station (BIRS) in the Canadian Rockies, 42 women mathematicians-graduate students, postdoctoral researchers, and senior women researchers who had formed groups of five or six several months in advance-spent five days working together on research problems posed in advance. A key factor in the success of the Research Networks is the publication of the articles produced by the working groups at the conference. In order to publish the research, typically the group has to continue working together for some months after the conference, and this helps form lasting bonds and collaborations.

The AWM has expanded the number of RCCWs each year, and has organized follow-up events and infrastructure to sustain and grow the resulting Research Networks

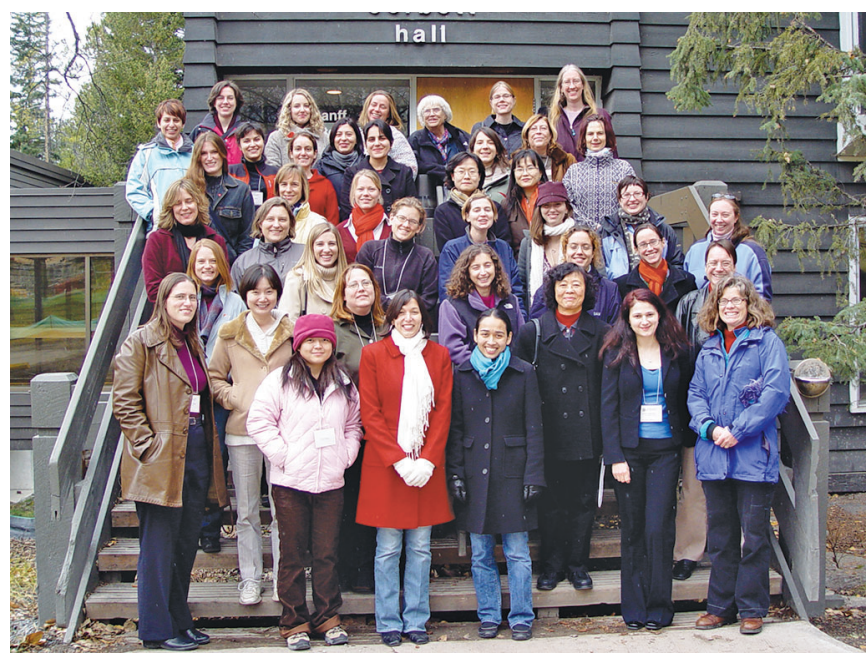

Figure 1.The firstWIN conference, BIRS, 2008. 
in various areas of mathematics. The co-PIs on the AWM ADVANCE grant were former AWM Presidents Kristin Lauter and Ruth Charney and former AWM Executive Director Magnhild Lien. Sociologist Erin Leahey served as senior personnel to study the impact of the program, and 2021-2023 AWM President Kathryn Leonard served on the Oversight Committee for the grant.

Several key elements of the Research Networks' structure foster their success:

- Women help each other through vertical integration-senior women mentor junior women on research problems and in their careers.

- Groups of women collaborators promote their joint work in the broader community by giving research talks and co-organizing conferences with many women speakers.

- Early-career women are encouraged and empowered to co-organize conferences with men and invite their women colleagues.

- Women have more opportunities to participate in the editorial and reviewing process at an earlier career stage through editing the proceedings volumes for the RCCWs.

- Junior and senior women participate in program committees to actively promote the inclusion of women speakers in major conferences and on editorial boards.

In sum, the AWM ADVANCE grant's Research Networks have created an army of women in many areas of mathematics who are empowered to work on behalf of themselves and other women to change the system by promoting each other's work in a manner that benefits everyone's career. They offer a way to circumvent the problem of women spending so much of their professional energy trying to help advance women and minorities that they fall behind male colleagues who have more time for research. In the AWM ADVANCE model, project leaders are essentially rewarded for effective mentoring by having excellent junior research collaborators who further and give increased visibility to the group leaders' research agendas as well as to their own nascent careers.

Each year since 2012, AWM Workshops at the annual JMM and SIAM meetings bring together women from one of the Research Networks to showcase their work and encourage continued collaboration and mentoring. The AWM also organizes biennial Research Symposia, with high-profile plenary speakers and special sessions in areas linked to the Research Networks.

An AWM committee accepts proposals for new networks twice a year - with deadlines of July 1 and January 1 . The committee then helps to refine proposals and match potential networks with a mathematics institute that will host the first collaboration conference for the network. Michelle Manes chaired this committee for three years and assisted in inaugurating many new networks, while also chairing the WIN Steering Committee.

In addition, Katherine Stange, who created the WIN website (https://womeninnumbertheory.org/), has helped Research Networks create their own websites and e-mail mailing listings, which are hosted by the AWM. These websites have increased the visibility of women in research mathematics, both for conference organizers to invite women speakers and for university hiring committees to increase the pool of women candidates.

An external evaluator, Dr. Erin Leahey, Professor of Sociology at the University of Arizona, is studying the efficacy of this model for advancing careers for women in mathematics for the five years of the grant, using workshop surveys (with more than 1,000 participants), conducting a career impact survey (with more than 400 respondents), and analyzing CVs; see [Lauter-Lien].

The WIN conferences have involved more than 250 women in number theory from around the world, were organized by more than 20 distinct women, and produced more than 50 peer-reviewed, published research papers in seven proceedings volumes that have appeared in the Fields Institute Series, the Centre Recherches Mathématiques (CRM) AMS Series, and the AWM Springer Series. When planning for the first WIN conference began, there were three women professors in number theory at top research universities in the US, whereas now there are several dozen women faculty in number theory.

Implementation of the AWM ADVANCE grant award has truly represented the collaborative work of many leading women in mathematics. It was the result of the collective efforts of at least six AWM Presidents and the AWM Executive Director, with inspiration from the Korean Women in Mathematical Sciences (KWMS), and countless organizers of focused Research Networks. The organizers of early RCCWs are listed in Table 5. Since Year 1 of the grant, 25 more RCCWs have been organized in many new and existing areas; these are not listed in Table 5, but they can be found on the RCCW tab on the AWM ADVANCE page. Organizing an RCCW is truly a labor of love, as well as a great deal of work, and so these organizers deserve to be named and celebrated.

Many of the RCCWs so far have taken place at BIRS, and the AWM is very appreciative of its substantial support. In addition to BIRS, the research institutes AIM, ICERM, IMA, and IPAM have all hosted RCCWs, and MSRI has launched an annual summer program for groups of women to collaborate on research projects, some of which may have started at RCCWs. Microsoft Research has generously cosponsored all of the AWM Research Symposia, the WIN Research Collaboration Conferences, and the RCCWs hosted at ICERM, IMA, and IPAM. Travel funding for participants has been provided by grants from the Clay Institute, NSA, NSF, PIMS, and the Number Theory Foundation, among others. 


\begin{tabular}{|c|c|l|c|}
\hline & Year & \multicolumn{1}{|c|}{ Organizers } & $\begin{array}{c}\text { Proceedings } \\
\text { published by }\end{array}$ \\
\hline WIN & 2008 & Kristin Lauter, Rachel Pries, Renate Scheidler & Fields Series \\
\hline WIN2 & 2011 & Chantal David, Matilde Lalin, Michelle Manes & CRM/AMS \\
\hline WINE & 2013 & Marie-Jose Bertin, Alina Bucur, Brooke Feigon, Leila Schneps & AWM \\
\hline WIN3 & 2014 & Ling Long, Rachel Pries, Katherine Stange & AWM \\
\hline WINE2 & 2016 & Irene Bouw, Rachel Newton, Ekin Ozman & AWM \\
\hline WIN4 & 2017 & Jennifer Balakrishnan, Chantal David, Michelle Manes, Bianca Viray & AWM \\
\hline WINE3 & 2019 & Sorina Ionica, Holly Krieger, Elisa Lorenzo Garcia & AWM \\
\hline WIN5 & 2020 & Alina Bucur, Wei Ho, Renate Scheidler & - \\
\hline
\end{tabular}

Table 4. WIN NumberTheory Conference organizers.

\begin{tabular}{|c|c|l|c|c|}
\hline & Year & \multicolumn{1}{|c|}{ Organizers } & $\begin{array}{c}\text { Proceedings } \\
\text { published by }\end{array}$ & Host \\
\hline ACxx & 2011 & Georgia Benkart, Stephanie van Willigenburg, Monica Vazirani & AWM & BIRS \\
\hline WiSh & 2013 & Kathryn Leonard, Luminita Vese & AWM & IPAM \\
\hline WIT & 2013 & Maria Basterra, Kristine Bauer, Kathryn Hess, Brenda Johnson & AMS & BIRS \\
\hline WhAM! & 2013 & Trachette Jackson, Ami Radunskaya & IMA & IMA \\
\hline WINASC & 2014 & $\begin{array}{l}\text { Susanne Brenner, Sigal Gottlieb, Chiu-Yen Kao, Hyesuk Lee, } \\
\text { Fengyan Li, Carol Woodward }\end{array}$ & IMA & IMA \\
\hline MathBio & 2015 & Anita Layton, Suzanne Lenhart, Laura Miller & AWM & NiMBioS \\
\hline WINART & 2016 & $\begin{array}{l}\text { Georgia Benkart, Ellen Kirkman, Susan Montgomery, Chelsea } \\
\text { Walton }\end{array}$ & - & BIRS \\
\hline WIT2 & 2016 & Maria Basterra, Kristine Bauer, Kathryn Hess, Brenda Johnson & J. Top. & BIRS \\
\hline WiSh2 & 2016 & $\begin{array}{l}\text { Erin Wolf Chambers, Asli Genctav, Evelyne Hubert, Kathryn } \\
\text { Leonard, Geraldine Morin, Sibel Tari, Noha El-Zehiry }\end{array}$ & AWM & METU \\
\hline
\end{tabular}

ACxx: Women in Algebraic Combinatorics, WiSh: Women in Shape Modeling, WIT: Women in Topology, WhAM!: Women in Applied Math, WINASC: Women in Numerical Analysis, WINART: Women in Noncommutative Algebra and Representation Theory.

Table 5. Early years of Research Networks by area.

Networks have also held their conferences at other research centers around the world, including Luminy (CIRM), the Lorentz Center, Nesin Village, Centre Henri Lebesgue, the Hausdorff Institute, the University of Leeds, Oaxaca (BIRS$\mathrm{CMO}$ ), and the Australian National University.

A significant portion of the funds from the AWM ADVANCE grant are devoted to participant expenses to attend these RCCWs or to speak at the AWM Workshops at JMM and SIAM and the special sessions for Research Networks at the biennial AWM Research Symposia.

\section{AWM Research Symposia}

To celebrate the fortieth anniversary of the AWM in 2011, Georgia Benkart, Kristin Lauter, and Jill Pipher organized a research symposium at Brown University/ICERM when Jill Pipher was AWM President and Founding Director of ICERM. This became the prototype for subsequent AWM Research Symposia, which are two-day weekend meetings, run on the model of the AMS sectional conferences, with high-profile plenary speakers and special sessions on focused research topics. Later supported by the AWM ADVANCE grant, the AWM Research Symposia have brought women mathematicians together to recognize their research achievements, build community, advance careers, and improve working conditions. Professional development activities include a panel on nonacademic careers, an exhibit hall, and networking opportunities. The subsequent AWM Research Symposia were held at Santa Clara University in 2013, the University of Maryland in 2015, UCLA/IPAM in 2017, Rice University in 2019, with the fiftieth anniversary symposium planned at the University of Minnesota/IMA, June 16-19, 2022.

40 Years and Counting: The AWM's Celebration of Women in Mathematics, in September 2011, drew an attendance of over 300 women and men and featured four invited talks, 18 sessions on a wide range of topics in pure and applied mathematics and mathematics education, and a total of 135 speakers. It received enormous help from the 
ICERM staff, funding from an NSF grant, and additional support from the AMS, Brown University, ICERM, the MAA, Microsoft Research, Pearson Education, SIAM, and the US Department of Energy. A day-long retreat at ICERM just prior to the meeting enabled the AWM Long-Range Planning Committee to reflect on the AWM's accomplishments, review its programs, and strategically plan for the future.

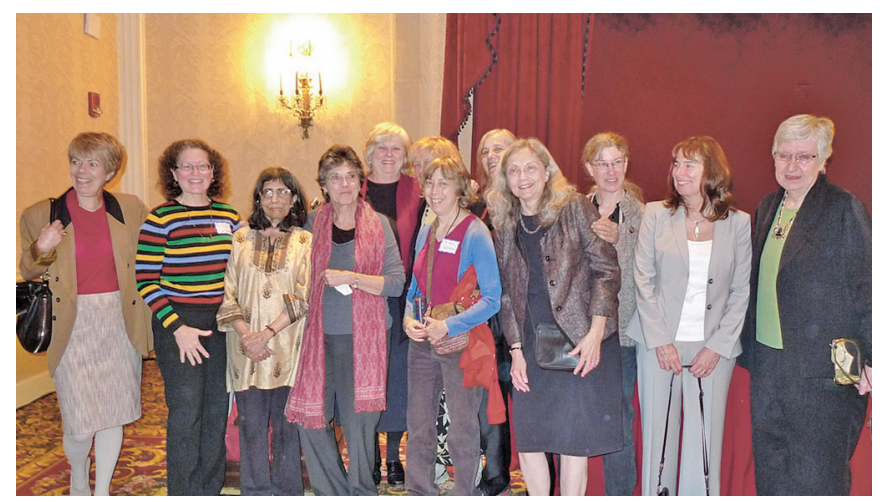

Figure 2. AWM Presidents at the fortieth anniversary conference.

AWM Research Symposium 2013 was organized by Hélène Barcelo, Estelle Basor, Georgia Benkart, Ruth Charney, Frank Farris, and Jill Pipher at Santa Clara University in 2013. It featured plenary talks by three distinguished mathematicians: Inez Fung, Professor of Atmospheric Sciences at UC Berkeley and an expert on the mathematics of climate; the late Maryam Mirzakhani, 2014 Fields Medalist; and Lauren Williams, now the Dwight Parker Robinson Professor of Mathematics at Harvard University. There were invited and contributed sessions on a wide range of subjects in pure and applied mathematics, a poster session for graduate students, and a discussion of "The Imposter Syndrome" moderated by Hélène Barcelo with panelists Ruth Charney, Brian Conrey, Jill Pipher, and Carol Wood.

AWM Research Symposium 2015, which took place at the University of Maryland in April 2015, was organized by Ruth Charney, Shelly Harvey, Kristin Lauter, Gail Letzter, Magnhild Lien, Konstantina Trivisa, and Talitha Washington. Many outstanding mathematicians volunteered to

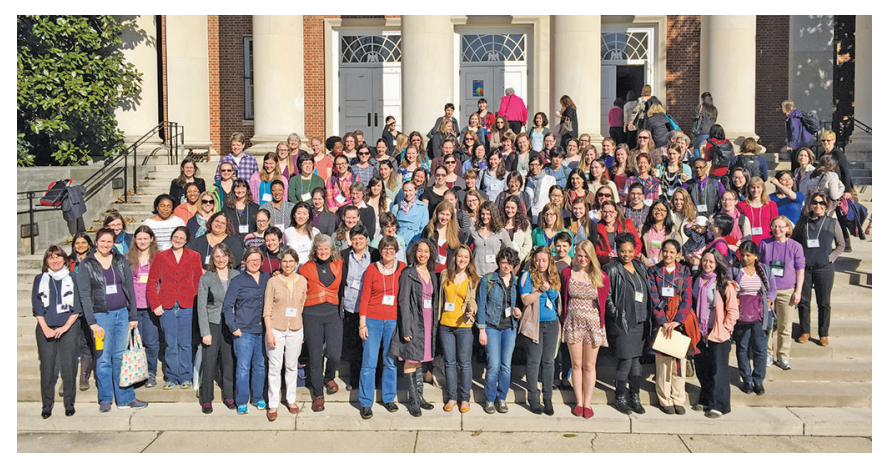

Figure 3. The AWM Research Symposium 2015, University of Maryland. organize the 14 special sessions representing a wide swath of mathematics, and plenary lectures were given by Ingrid Daubechies, Maria Chudnovsky, Jill Pipher, and Katrin Wehrheim. First Lady Michelle Obama was invited as the banquet speaker, but was unable to attend.

The format of the 2015 symposium was similar to those at ICERM and Santa Clara, but also included an employment panel moderated by Gail Letzter with representatives from industry and government, prizes for outstanding posters, and presentation of the inaugural AWM Presidential Award. The Award was given to the founders of the EDGE (Enhancing Diversity in Graduate Education) Program, Sylvia Bozeman and Rhonda Hughes, in recognition of the EDGE Program's strong record of supporting graduate students and building community among women from diverse backgrounds. Shirley Malcom, head of the Office of Opportunities in Science at AAAS, delivered an inspiring keynote address, followed by moving acceptance speeches from Sylvia Bozeman and Rhonda Hughes.

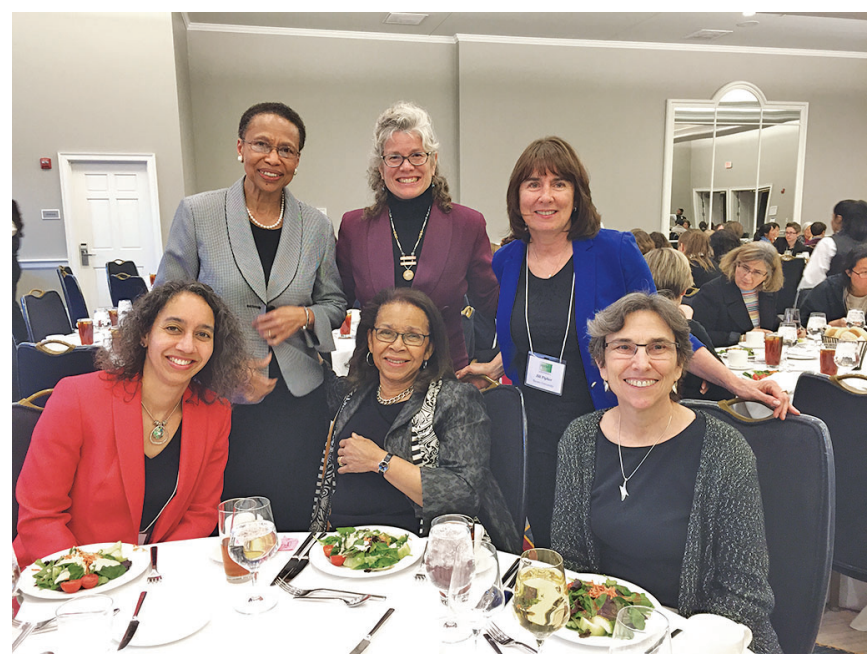

Figure 4. Banquet at the 2015 AWM Research Symposium with AWM Presidential Award winner Sylvia Bozeman, former AWM Presidents Kristin Lauter and Jill Pipher (in the top row), former AWM Executive Committee memberTalitha Washington, 2015 Keynote Speaker Shirley Malcom, and former AWM President Ruth Charney in the bottom row.

AWM Research Symposium 2017, supported by the NSF ADVANCE grant and held April 7-9, 2017, at UCLA/ IPAM, was co-organized by Reagan Higgins, Kristin Lauter, Magnhild Lien, Ami Radunskaya, Tatiana Toro, Luminita Vitse, and Carol Woodward.

Plenary speakers were AWM Past President Ruth Charney, AWM Sadosky Prize winner Svitlana Mayboroda, Blackwell-Tapia Prize winner Mariel Vazquez, and the first AWM/SIAM Sonia Kovalevsky Lecturer Linda Petzold. The 2nd AWM Presidential Award honored Deanna Haunsperger, then President-Elect of the MAA, for her enduring contribution to advancing the mission of the AWM by establishing and running the Summer Math 


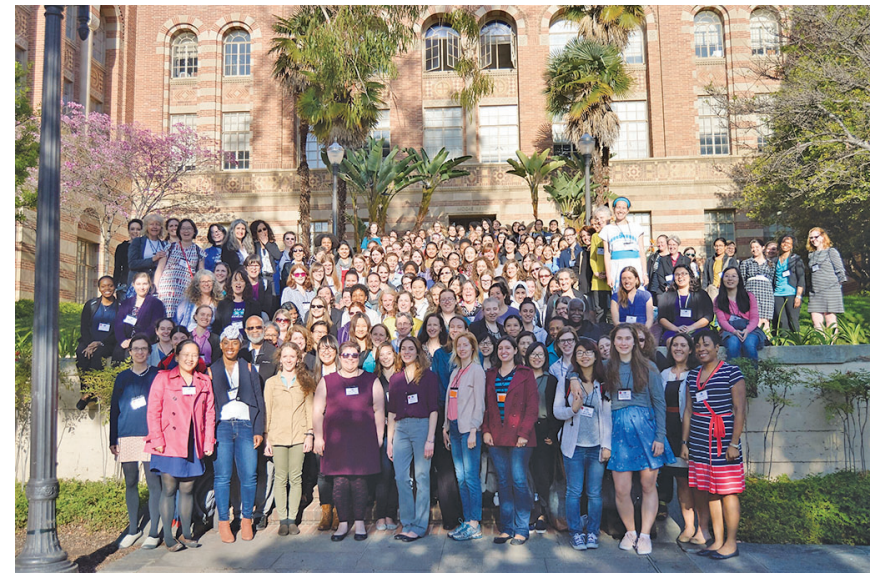

Figure 5. 4th AWM Research Symposium, UCLA/IPAM, 2017.

Program at Carleton College. IPAM hosted a welcoming event for students and the AWM Student Chapters, and the first Wikipedia edit-a-thon was led by Marie Vitulli and Ursula Whitcher to create Wikipedia pages for women in mathematics. Following a lunch presentation and discussion on establishing new AWM Research Networks by Magnhild Lien and Kristin Lauter, several new networks were formed. The Notices published the 2017 AMS Notices Sampler for the 2017 AWM Symposium.

AWM Research Symposium 2019, at Rice University April 6-7, 2019, attracted more than 350 attendees. Of the 20 special sessions in different research areas, 13 were organized by Research Networks supported by the ADVANCE grant. Plenary lectures were given by Susanne Brenner, Kristin Lauter, and Chelsea Walton, the banquet included a welcome from Rice Provost Marie Lynn Miranda, and a keynote address by a Rice undergraduate Mariam Manuel. The Wikipedia edit-a-thon, the career panel focusing on mathematicians in government and industry, and the lunch presentation on establishing and maintaining AWM Research Networks were carried over from 2017. The NSF AWM ADVANCE grant provided more than $\$ 70,000$ in participant support for each of the 2017 and 2019 symposia, plus administrative funds and overhead support for the AWM.

The 2022 AWM Research Symposium celebrating the fiftieth anniversary of the AWM is to be hosted by the IMA (Institute for Mathematics and its Applications) in partnership with the University of Minnesota, June 16-19, 2022.

The Research Symposia, while requiring many hands and significant funding to realize, have proved to be invaluable for building community among female mathematicians, showcasing women's work in mathematics, and attracting attention, support, and sponsorship for the AWM mission. Proceedings volumes for the 2015, 2017, and 2019 symposia published in the AWM Springer Series highlight the events and the research.

\section{AWM Springer Series}

AWM launched the AWM Springer Series in 2014 to publish the proceedings of the Research Collaboration Conferences for Women, AWM Workshops, AWM Research Symposia, and other AWM events and panels. A list of the 23 volumes published to date is available on the series webpage. They include four volumes from the WIN conferences, several volumes each from WiSh (Women in Shape Modeling), WIMB (Women in Math Biology), and other networks, three volumes from the 2015, 2017, and 2019 AWM Research Symposia, one volume on mathematics education based on an AWM-AMS panel at the Joint Mathematics Meetings, a history of women in mathematics based on an AWM Contributed Papers session at MAA's hundredth anniversary celebration at MathFest in 2015, and two volumes on Harmonic Analysis in honor of the late AWM President Cora Sadosky (1940-2010).

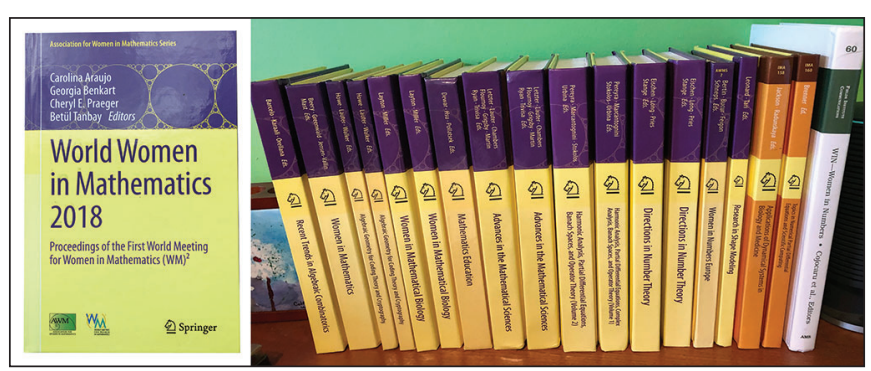

Figure 6. Proceedings volumes from RCCWs in the AWM Springer Series.

\section{AWM Capitol Hill Visits}

When the 2015 AWM Research Symposium was hosted at the University of Maryland, then AWM President Kristin Lauter invited all AWM Executive Committee (EC) members to join her in a day of visits to Capitol Hill on April 13, 2015, the day after the symposium. EC Member and Professor at Howard University Talitha Washington accepted Lauter's invitation. They made appointments, introduced themselves and the AWM, and discussed STEM outreach funding and initiatives with Congresswoman Eddie Bernice Johnson, and with congressional staff in the offices of Senator Kirsten Gillibrand, Senator Patty Murray, and Congressman Paul Tonko. Representative Johnson asked for a list of women in mathematics who would be willing to speak at local events in her district in Dallas. They also discussed Representative Tonko's bill, H.R.823 - Educating Tomorrow's Engineers Act of 2015, and President Obama's initiative to increase the STEM workforce. In a follow-up phone meeting with the White House Council on Women and Girls, they proposed that the AWM Essay Contest Winner be invited to the annual White House Science Fair.

These visits began the shaping of a broader advocacy agenda for the AWM that reflects the AWM's mission of advancing women and girls in mathematics. In August 2015, when much of the AWM leadership returned to 


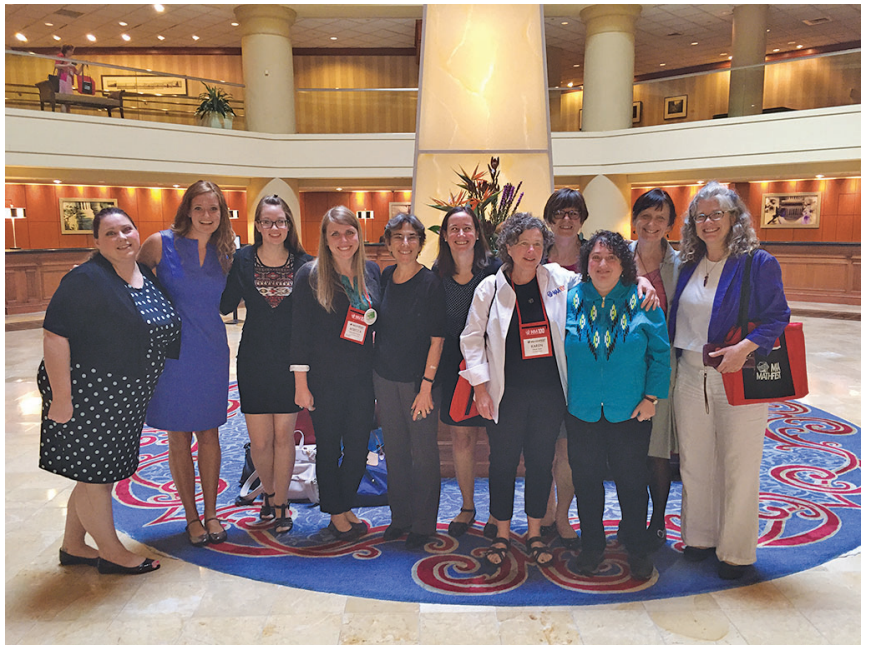

Figure 7. Heading to the Hill: students gather with AWM leadership at the MAA's MathFest, August 2015.

Washington for the MAA's MathFest, the Hill visits were planned to include leaders from AWM Student Chapters (at UT Arlington, Clemson, Colorado School of Mines, James Madison, Clarkson, Georgia College), who were participating in a special poster session at MathFest organized by Kathleen Fowler. Karen Saxe, Associate Executive Director of the AMS and its Director of the Office of Government Relations, was invited to provide background materials and an hour-long, in-person training session for the students and AWM leadership before heading to the Hill.

Three groups led by President Kristin Lauter, Executive Director Magnhild Lien, and Past President Ruth Charney visited offices from districts where the students were constituents. They discussed the STEM Gateways Act $\left[114^{\text {th }}\right.$, S.1183 \& H.R. 840] introduced by Senator Gillibrand and Representative Kennedy, which aimed to increase the participation of women, girls, and underrepresented minorities in STEM fields by authorizing the Department of Education to create a competitive grant program. They also registered support for the STEM Opportunities Act of 2015 [114 ${ }^{\text {th }}$ H.R.467] introduced by Representative Eddie Bernice Johnson, to require federal agencies both to collect more comprehensive demographic data on the recipients of federal research awards and on STEM faculty at US universities and to promote data-driven research on the participation and trajectories of women and underrepresented minorities in STEM. These visits had been advertised in the AWM Newsletter, inviting broader participation, and the students involved in them published an article for the Newsletter detailing the visit and posted photos on the AWM Facebook page.

In late 2015, AWM leadership consulted the AWM Advisory Board to propose setting up a regular program of Hill visits, and Board Chair Mary Gray proposed working through the AWM Policy and Advocacy (P\&A) committee. That year, Gail Letzter was elected to the AWM Executive
Committee and agreed to serve as Chair of the P\&A Committee and to formally establish the program with the help of Karen Saxe, who also joined the committee. Together they led the P\&A to develop a more comprehensive policy agenda and legislative priorities, as well as a regular cadence of visits twice a year to coincide with the Conference Board of the Mathematical Sciences meetings in Washington, DC, in May and December. The legislative priorities formulated by the P\&A Committee, published in the July/August 2016 issue of the AWM Newsletter, were:

1. Expand STEM educational opportunities.

2. Support research funding.

3. Improve work/life balance: expand child-care and family leave options.

4. Modernize self-perpetuating mechanisms that limit public recognition of women's achievements.

5. Create a welcoming environment in science and education, including policies to address sexual harassment and violence on university campuses.

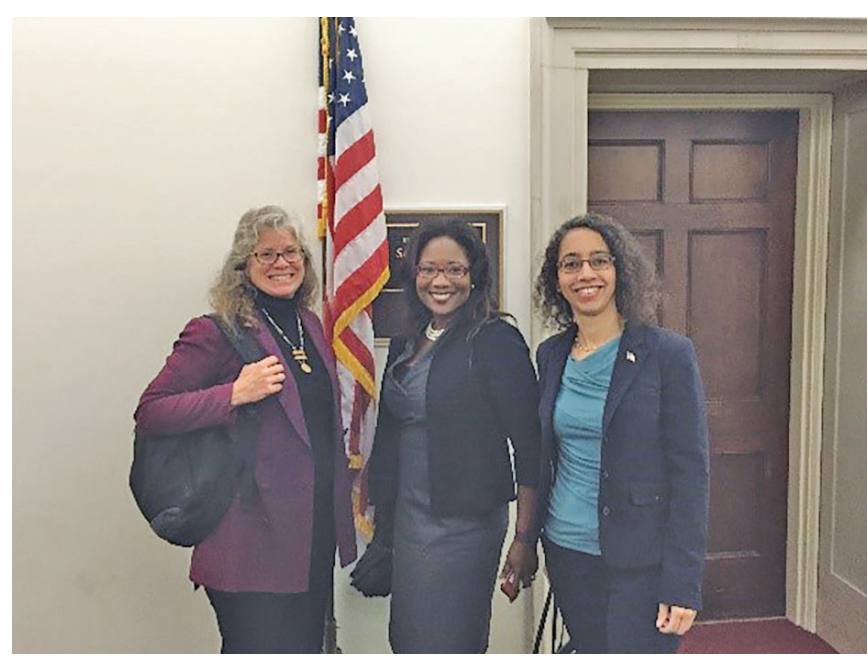

Figure 8. Lauter with Talithia Williams and Talitha Washington in DC.

In May 2016, AWM President Kristin Lauter was accompanied on the third AWM Hill visit by EC Members Talitha Washington and Talithia Williams to discuss the AWM legislative agenda with staff in the offices of Congresswomen Barbara Lee and Jackie Speier, and to support the bill "Computer Science for All" introduced by Representative Lee and several cosponsors. In Fall 2016, Representative Speier introduced H.R.6161 - Federal Funding Accountability for Sexual Harassers Act, and her office invited the AWM contingent to meet with her again during the December 2016 visit.

The December 2016 visit was the most exciting and successful visit to date. Beth Malmskog and Katherine Haymaker, faculty mentors for the AWM Student Chapter at Villanova, brought nine students from Philadelphia to join the AWM Hill Day on December 1. The AWM contingent 
attended a breakfast hosted by Pennsylvania Senator Bob Casey, visited more than 20 congressional offices in groups, and met several other Members of Congress on both sides of the aisle. The top legislative priority was the Women and Minorities in STEM Booster Act of 2016. The AWM groups also voiced support for the Computer Science for All Initiative, the INSPIRE Women Act, and the bill introduced by Representative Speier requiring that sexual harassment by Principal Investigators be reported to funding agencies, and that harassment reports be considered when awarding federal funding.

The visit was captured enthusiastically by Beth Malmskog in her AMS blogpost. There is evidence that the AWM's Hill visits have had an impact through the legislation that the association has supported. Representative Eddie Bernice Johnson spoke about AWM support for one of her bills on the floor of the House. However, possibly the greater impact the program has had is on the women and men of the AWM and AWM Student Chapters who have participated in these visits, empowering and inspiring them to continue to make a difference by supporting each other and fighting for change. Some student participants even said that taking part in the day-long Hill visit had "changed their lives." In 2017, Gail Letzter and Karen Saxe created a subcommittee in the P\&A Portfolio, the Government Advocacy Committee, to run the Hill visits. The subcommittee is now chaired by Executive Committee member Michelle Snider and the visits continue.

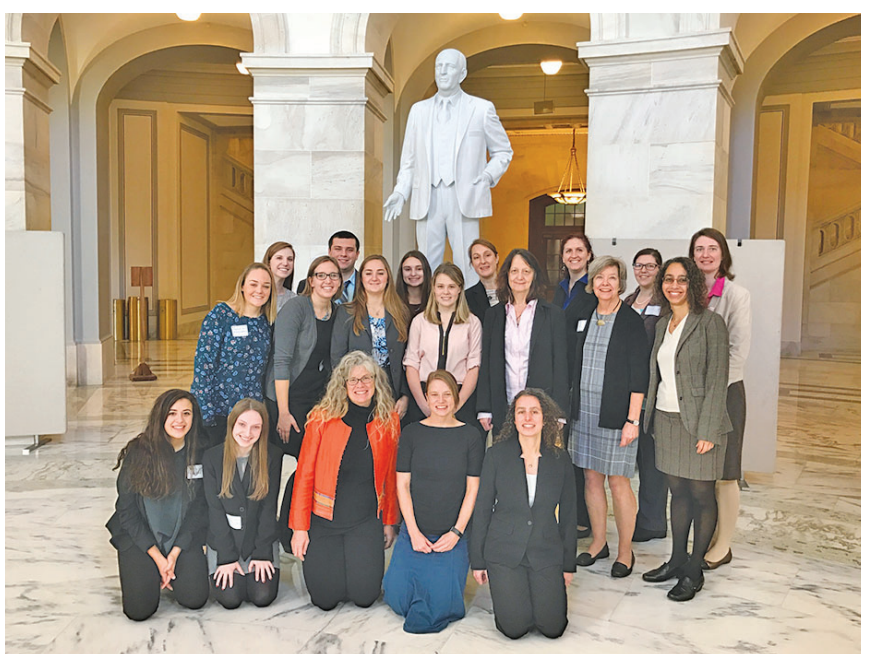

Figure 9. On Capitol Hill: Villanova AWM Student Chapter with AWM leadership, December 2016.

\section{AWM Student Chapters}

AWM Student Chapters at colleges and universities are one of the association's greatest assets. They provide a way to advance its mission by building community, supporting education and developing careers of students, and advocating for women in mathematics on college campuses. There

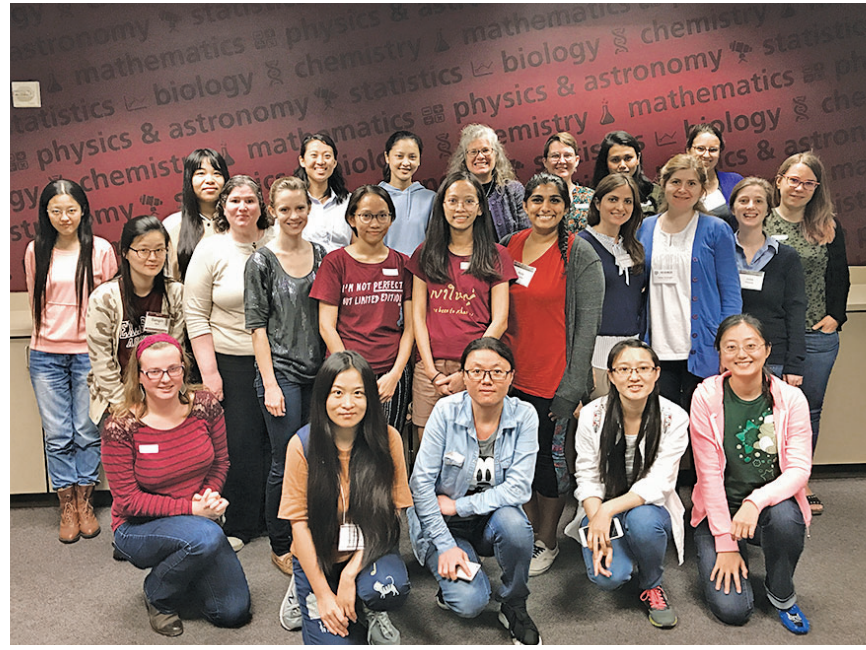

Figure 10. AWM Student Chapter atTexas A\&M University, 2017

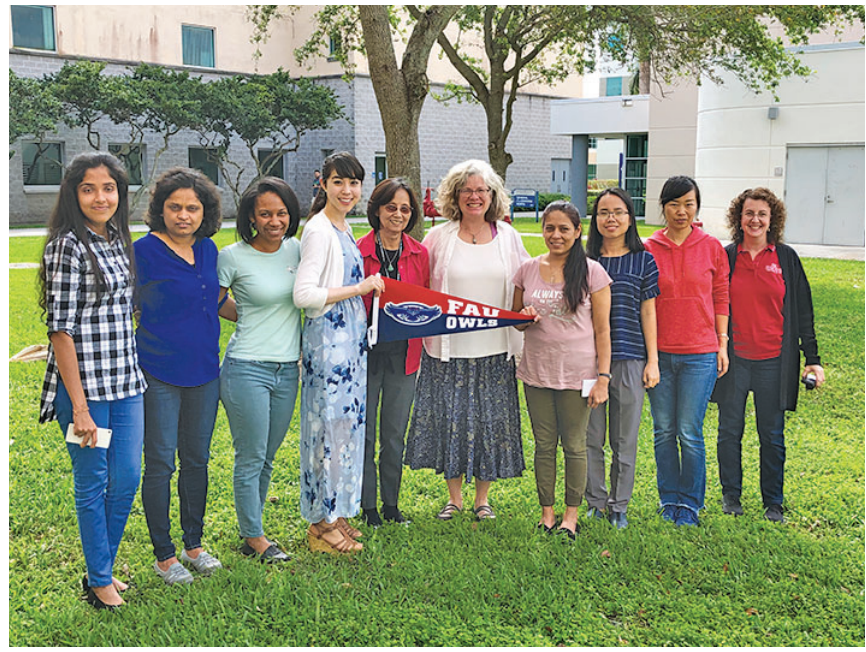

Figure 11. AWM Student Chapter at Florida Atlantic University, 2019.

are currently more than one hundred active AWM Student Chapters. In 2015, an annual webinar was begun for Student Chapter Presidents to meet with the AWM President and discuss ideas with each other. Newsletter Editor Anne Leggett resurrected a "Student Chapter corner" in the Newsletter to publish articles from the chapters on their activities, and online folders for chapters were created to share ideas and information. The AWM Awards Committee developed annual Student Chapter Awards in four categories: Community Outreach, Fundraising and Sustainability, Professional Development, and Scientific Excellence. Nominations are due by April 15 each year, and chapters can self-nominate for the awards, which are presented each summer at a reception at MathFest. Student Chapter members also are invited to attend the AWM Reception at the JMM to meet with Executive Committee members and network. 


\section{Social Media}

When Jill Pipher was AWM President (2011-2013), the AWM launched a Facebook page. In January 2015, an ad hoc Media Committee was formed to improve communication with members, to reach and attract new members, to raise the profile and awareness of the AWM in the mathematics community and in the public, to draw media attention to AWM events, and to attract more corporate sponsors for the organization and its initiatives. That committee, chaired by Web Editor Adriana Salerno, included Anna Haensch, Marie Vitulli, Talitha Washington, Newsletter Editors Anne Leggett and Sarah Greenwald, Executive Director Magnhild Lien, and AWM President Kristin Lauter. One of the first actions of the new committee was to launch the AWM Twitter feed, @AWMmath. The 2015 AWM Research Symposium was liveblogged and tweeted by Salerno and Haensch. The AWM ADVANCE program also launched an active Twitter feed: aAWMadvance. EC member Marie Vitulli later became AWM Media Coordinator and posted daily content to the AWM Facebook page, providing stimulating topics for discussion, interspersed with biographies of women in mathematics and updates on the activities of the AWM and women in the profession.

\section{Awards}

One of the biggest barriers to the advancement of women in mathematics and science is a lack of visibility and recognition for the vast talent, contributions, presence, and hard work of women in the field. It is therefore important to shine the light on those women and their contributions, by increasing the number of pictures of women mathematicians in publications and on social media and by seeing that women's work is recognized through the prizes awarded by the major professional societies.

For this reason, the AWM has instituted its own prizes and recognitions and has strived to nominate women for awards conferred by other professional societies. The AWM Sadosky Prize in Analysis and the AWM Microsoft Research Prize in Algebra and Number Theory were established in 2012 and first awarded in 2014, and the AWM Joan and Joseph Birman Research Prize in Topology and Geometry was established in 2013 and first awarded in 2015. The AWM Dissertation Awards were developed by Rhonda Hughes in the Awards Committee and approved by the Executive Committee in January 2016. Announced annually at the AWM reception at the JMM, these four prizes call attention to the work of outstanding early-career women and the dissertation accomplishments of $\mathrm{PhD}$ students.

AWM Service Awards have been given each year since 2013, to acknowledge the AWM's great reliance on the dedication of its volunteer members and, in particular, on the efforts of those who step up year after year for intensive immediate projects. The reason for instituting these awards was evident, but the AWM had recognized some outstanding contributions prior to their establishment. At the fortieth anniversary celebration at JMM 2011, for example, Bettye Anne Case, AWM's longtime Meetings Coordinator, and Anne Leggett were honored for their exceptional service to the AWM. Anne has been the AWM Newsletter editor for over forty years and continues her stellar work in that essential role today.

\section{AWM Scientific Advisory Committee}

In order to ensure that outstanding work by women in mathematics is also recognized by other societies through prizes, fellow nominations, and named lectures, Past President Sylvia Wiegand chaired the Awards Committee and worked with President Ruth Charney to create the AWM Scientific Advisory Committee, approved by the Executive Committee in January 2015. The committee of six members serving staggered three-year terms was charged with generating names and procuring nominations for women to be recipients of the distinguished prizes, awards, and honors of organizations related to the mathematical sciences, including the AMS, MAA, SIAM, and AWM.

Charney chaired the committee for the first year and Wiegand for the next year, and the other inaugural members were Georgia Benkart, Suncica Canic, Barbara Keyfitz, and Susan Montgomery. The committee generated numerous nominations for highly deserving women, especially for AMS and SIAM Fellow recognition.

The Awards and Scientific Advisory Committees have advocated for more nominations of women for awards and recognition in the mathematical sciences; the percentages of women among recipients of awards and recognition would be rather low if the AWM did not advocate for women. For example, of the 12 women in the 2020 class of 52 AMS Fellows, at least six were bolstered by the AWM committee's organized efforts to document their qualifications and support their selection.

\section{AWM Fellows Program}

Although the AWM Scientific Advisory Committee has helped to nominate many deserving women for awards, there remain so many talented women mathematicians and educators whose work is not sufficiently celebrated and encouraged. Consequently, when Sylvia Wiegand was chair of the Advisory Committee, she and Past President Rhonda Hughes proposed that an AWM Fellows Program be created to recognize those with sustained contributions to the AWM's mission of supporting women and girls in mathematics. Joan Ferrini-Mundi chaired the Awards Committee in 2016, and the AWM Fellows Program was approved in January 2017. Carol Woodward chaired the next Awards Committee that defined the terms of the program. The inaugural class of fellows was celebrated at the AWM reception at the JMM in January 2018. 


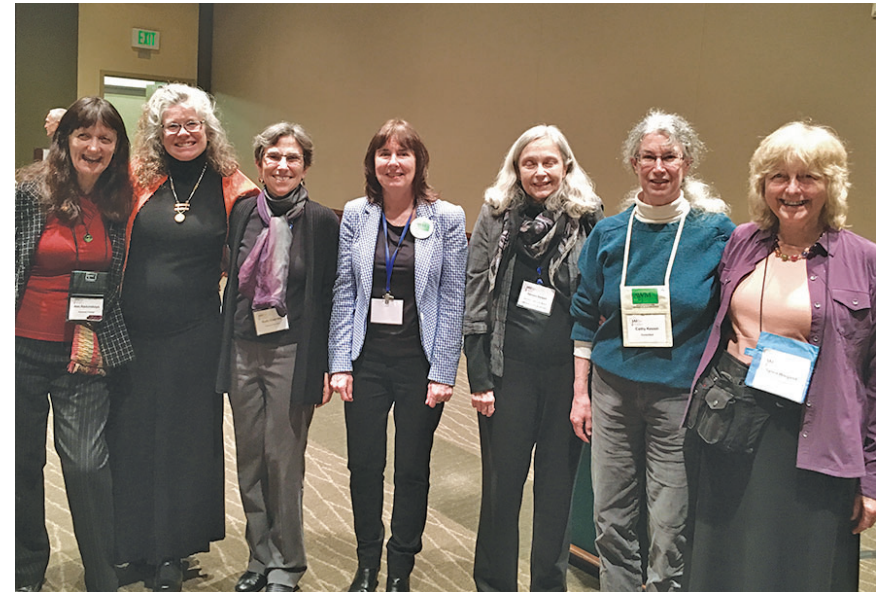

Figure 12. Seven Presidents in a Row at the AWM reception at JMM, January 2016: Ami Radunskaya, Kristin Lauter, Ruth Charney, Jill Pipher, Georgia Benkart, Cathy Kessel, Sylvia Wiegand.

\section{Conclusion}

The AWM offers everyone in the mathematical community the opportunity to become involved and help advance women and girls in mathematics. Anyone can start or join an AWM Student Chapter or a Research Network for women, become a mentor, get a mentor, publish in the AWM Springer Series, or attend an AWM workshop at the JMM or the SIAM annual meeting! We hope to see you at the AWM Research Symposium in 2022*, and Happy Fiftieth Anniversary to the AWM!

\section{References}

[AMS Stats] Statistics on Women Mathematicians; Compiled by the AMS, Notices Amer. Math. Soc. 62 (2015), no. 9, 1055.

[Golbeck-Barr-Rose] A. L. Golbeck, T. H. Barr, and C. A. Rose, Report on the 2016-2017 New Doctorate Recipients, Notices Amer. Math. Soc. 66 (2019), no. 7, 1153-1160.

[Lauter-Lien] K. Lauter and M. Lien, AWM Advances! Year 2, AWM Newsletter 48 (May-June 2018), no. 3, 15-21.

[Taylor-Wiegand] J. E. Taylor and S. Wiegand, AWM in the 1990s: A recent history of the Association for Women in Mathematics, Notices Amer. Math. Soc. 46 (1999), no. 1.

[Topaz-Sen] C. Topaz and S. Sen, Gender representation on journal editorial boards in the mathematical sciences, PLoS ONE 11 (2016), no. 8: e0161357, https://doi.org/10.1371 /journal. pone.0161357.

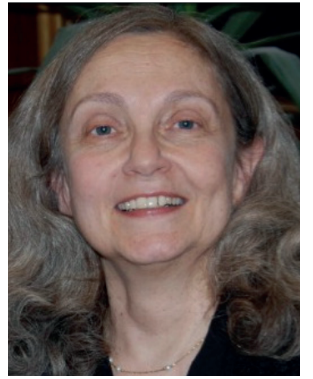

Georgia Benkart

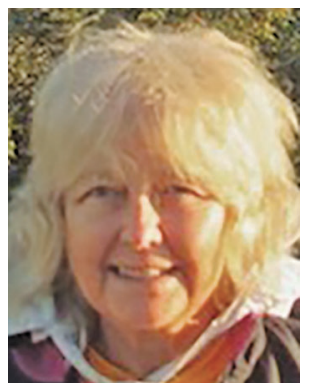

SylviaWiegand

\section{Credits}

Figure 1 is courtesy of Kristin Lauter.

Figure 2 is courtesy of Jennifer Quinn.

Figures 3-12 are courtesy of Kristin Lauter.

Photo of Georgia Benkart is courtesy of Yvonne Nagel.

Photo of Kristin Lauter is courtesy of Michael Svoboda/Microsoft Research.

Photo of Sylvia Wiegand is courtesy of Ajaya Singh.

\footnotetext{
*The AWM Research Symposium originally scheduled for June 2021 has been postponed until June 16-19, 2022. For up-to-date information see https://awm-math.org/meetings/awm-research-symposium/.
} 